\title{
Reply to Ortiz and Ames' \\ Viewpoint: Sample adequacy for point analysis depends on the objectives
}

\author{
L. HOFMANN AND R.E. RIES
}

\begin{abstract}
Authors are research agronomist and range scientist, Northern Great Plains Laboratory, P.O. Box 459, Mandan,
\end{abstract} ND 58554.

We conducted our study (Hofmann and Ries 1990) after numerous questions from regulatory agencies and mining companies concerning the use of sample size adequacy formulas to determine the number of points needed to estimate ground cover. They noted that when the recommended equation was applied to some ground cover measurements, an excessive number of frames were required to meet federal statistical requirements. In response, we conducted sampling trials to determine how means of various cover components would be changed by the number of point frames taken. Our purpose was not to provide an alternate formula to reduce sampling requirements or to help prove successful reclamation. We analyzed sample size equations; studied the problem of excessive point numbers; provided, with limitations, a statistically sound explanation of why the recommended formula caused problems; and then proposed a solution to the problem of excessive sample size requirements.

The viewpoint of Ortiz and Ames expresses several "minor quibbles". It noted that " $\bar{x}$ is an unbiased estimate of $\mu$ " and that "on average the mean of the $\vec{x}$ 's is the population mean regardless of the sample size". This is essentially (within limitations) what we concluded and stated when we discussed the consistency of the means.

Regarding normal population and binomial distribution, both the literature and our sampling results show that some components of biological communities are indeed non-normally distributed. Bonham (1989) noted that "presence-absence type of data for a plant characteristic" give rise to a "point binomial" distribution. Also, clustered plant field data may be a "count binomial" or "Poisson" distribution.

We agree that a set value for the denominator " $d$ " in the equation is quite different than a required $10 \%$ of the mean. Chambers and Brown (1983), Steel and Torrie (1980), and Cochran (1977) suggested that the value of " $d$ " should be a fixed width of the size difference we wish to detect; therefore, we used a fixed width for the value of " $d$ " in our paper.

The major argument of the viewpoint appears to be a question of whether sample size can be used to prove reclamation. The purpose of our study, as stated in the paper was, "to determine how the number of point frame samples affects the estimated mean and variance of ground cover components and to examine how sample size estimates calculated by the equation (1) change as sample size changes." Our study was not undertaken or designed to answer whether it is proper to use sample size as a criterion to prove reclamation.

Contribution from Northern Great Plains Research Laboratory, USDA-ARS.

Manuscript accepted 31 Aug. 1992.
The viewpoint illustrates the limitation of using only sample size and mean confidence widths to prove reclamation. Regulatory agencies are probably aware of these limitations as well. In addition to sample size requirements, regulatory agencies also require an additional statistical test, such as the $t$-test, to determine whether cover of a reclaimed area is within $10 \%$ of the cover on a reference area or other approved standard.

The concerns of Ortiz and Ames underscored the intent of our paper, i.e., to show that in point analysis of ground cover, statistical formulas to determine sample size, based on normal distribution, are of questionable value for estimating point numbers to prove successful reclamation of a mining site according to government regulations. The viewpoint presents problems and arguments that can occur when point numbers are used to provide statistical confidence to cover data. Other statistical tests that compare means are more appropriate. However, there should be some guideline so that an adequate number of samples are taken.

Our sampling data and the literature (Levy 1933, Drew 1944, and Crocker and Tiver 1948) suggest that 400 to 500 points are adequate to sample cover on areas with similar range sites or plant community, regardless of the area size. Sample size formula and requirements cause disagreement, excessive sampling input, and as Ortiz and Ames point out, a questionable conclusion. Sample size requirements could be omitted from regulatory criteria because other statistical tests such as confidence intervals, $t$-tests, or ANOVA that compare the mean of reclaimed areas and reference areas are a more appropriate solution to the problem.

\section{Literature Cited}

Bonham, C.D. 1989. Measurements for terrestrial vegetation. John Wiley \& Sons. New York.

Chambers, J.C., and R.W. Brown. 1983. Methods for vegetation sampling and analysis on revegetated mined lands. Gen. Tech. Rep. INT-151. Ogden, Ut. USDA Forest Serv.

Cochran, W.G. 1977. Sampling techniques. 3rd. ed. John Wiley and Sons. New York.

Crocker, R.L., and N.S. Tiver. 1948. Survey methods in grassland ecology. J. Brit. Grassl. Soc. 3:2-26.

Drew, W.B., 1944. Studies on the use of the point-quadrat method of botanical analyses of mixed pasture vegetation. J. Agr. Res. 69:289-297.

Hofmann, L., and R.E. Ries. 1990. An evaluation of sample adequacy for point analysis of ground cover. J. Range Manage. 43:545-549.

Levy, E.B. 1933. Technique employed in grassland research in New Zealand. Imp. Bur. Plant Genet. Herb. Plants Bull. 11:6-16.

Steel, R.G.D., and J.H. Torrie. 1980. Principles and procedures of statistics. Second ed. McGraw-Hill Book Co., New York, N.Y. 